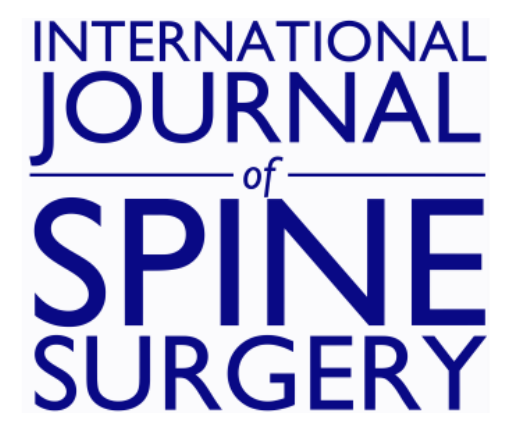

\title{
Hemorrhagic thoracic schwannoma presenting with intradural hematoma and acute paraplegia after spinal manipulation therapy
}

Alia Hdeib, C. Rory Goodwin, Daniel Sciubba, Ali Bydon, Jean-Paul Wolinsky, Timothy Witham and Ziya L. Gokaslan

Int J Spine Surg 2016, 10 ()

doi: https://doi.org/10.14444/3042

http://ijssurgery.com/content/10/42

This information is current as of April 26, 2023.

Email Alerts Receive free email-alerts when new articles cite this article. Sign up at:

http://ijssurgery.com/alerts

The International Journal of Sowine Surgerh http://ijssurgery.com/ by guest on April 26, 2 2397 Waterbury Circle, Suite 1,

Aurora, IL 60504, Phone: +1-630-375-1432

(C) 2016 ISASS. All Rights Reserved. 


\section{Hemorrhagic thoracic schwannoma presenting with intradural hematoma and acute paraplegia after spinal manipulation}

\section{therapy}

Alia Hdeib, MD, 1,2 C. Rory Goodwin, MD, Ph.D., ${ }^{1}$ Daniel Sciubba, MD, ${ }^{1}$ Ali Bydon, MD, ${ }^{1}$ Jean-Paul Wolinsky, MD, ${ }^{1}$ Timothy Witham, MD, ${ }^{1}$ Ziya L. Gokaslan, $M D^{1,3}$

${ }_{1}$ Johns Hopkins University School of Medicine, Department of Neurological Surgery, Baltimore, MD 2University Hospitals Case Medical Center, Department of Neurosurgery, Case Western Reserve University School of Medicine, Cleveland, OH ${ }^{3}$ The Warren Alpert Medical School of Brown University, Department of Neurosurgery, Providence, RI

\section{Abstract}

Hemorrhagic conversion of spinal schwannomas represents a rare occurrence; also rare is the development of a spinal intradural hematoma after spinal manipulation therapy. We report a unique presentation of paraplegia in a patient who underwent spinal manipulation therapy and was found to have a hemorrhagic thoracic schwannoma at time of surgery in the setting of anti-platelet therapy use. In patients with spinal schwannomas, tumor hemorrhage is a rare occasion, which can be considered in the setting of additive effects of spinal manipulation therapy and antiplatelet therapy.

KEYWORDS: THORACIC SCHWANNOMA, HEMORRHAGIC SCHWANNOMA, SPINAL SCHWANNOMA, INTRADURAL SPINAL HEMORRHAGE VOLUME 10 ARTICLE 42 DOI: 10.14444/3042

\section{Introduction}

Spinal nerve sheath tumors include schwannomas and neurofibromas, representing commonly encountered spinal tumors. Annually primary spinal neoplasms account for an incidence of 1.3 to 10 per 10,000 population and nerve sheath tumors can represent a third of these. ${ }^{1,2}$ Spinal nerve sheath tumors account for $30 \%$ of all intradural tumors. ${ }^{1}$ Spinal schwannomas are usually extramedullary and can be either intradural, extradural, or both. Spinal nerve sheath tumors often occur between the ages of 25 to 50 , with no significant predilection for gender. ${ }^{2,3}$ Common presenting symptoms depend on location and often attributable to direct compression of the spinal cord / cauda equina and / or the nerve root of origin of the neoplasm. Symptoms include motor symptoms due to mechanical compression from the tumor, pain, parasthesias and numbness. ${ }^{2,3}$ Occasionally these tumors are found incidentally on imaging and may be asymptomatic.

Hemorrhagic conversion of a schwannoma is not a common initial presentation; acute paraplegia due to acute hemorrhagic conversion of a spinal schwanno$\mathrm{ma}$ is a rare occurrence. In addition spinal intradural hematoma after spinal manipulation therapy is also a rare occurrence and the literature lacks reports of inDownloaded from http://ijssurgery.com/ by guest on April 26, 2023 tradural hemorrhage following spinal manipulation. We present a clinic case of acute paraplegia due to hemorrhagic conversion of an intradural thoracic schwannoma presenting with compressive intradural hematoma after spinal manipulation therapy, and a review of the literature for factors predisposing to hemorrhagic conversion.

\section{Case Illustration}

\section{Initial Presentation}

A 71 year-old man with a past medical history significant for hypertension, hyperlipidemia, and benign prostatic hyperplasia underwent spinal manipulation therapy by a chiropractor for back pain complaints. He was taking nonsteroidal anti-inflammatory medications (NSAIDs) and reporting daily aspirin use. The spinal manipulation therapy treatment was performed at an outside facility and specific techniques were not available for review from the practitioners. Throughout the course of the day, following spinal manipulation therapy, the patient developed right then left lower extremity weakness and urinary retention. He presented to an emergency department, and upon transfer to a tertiary care center he was noted to have profound weakness in the lower extremities with some distal toe movement but otherwise no significant lower extremity movement, 
patchy sensation in right proximal leg, and full strength in the upper extremities. An MRI was obtained at time of presentation; sagittal non-contrast images were available for review. MRI imaging showed a $1.4 \mathrm{~cm}$ intradural extramedullary lesion along the posterior thecal sac compressing the thoracic spinal cord at the T8 level with foci of T2 hypointensity and foci of $\mathrm{T} 1$ hyperintensity concerning for blood products (Figure 1).

\section{Hospital Course}

The patient was offered emergent surgery for exploration and decompression of the thecal sac. Coagulation parameters at time of presentation were within normal limits. He underwent a thoracic laminectomy, exploration of the subdural space, evacuation of a compressive intradural hematoma and resection a of thoracic schwannoma. Upon exploration of the intradural space, a thick area of compressive clot was noted, along with a traversing nerve root noted to have a reddish-tan colored small growth adherent to the clot, concerning for a nerve sheath tumor. The clot was evacuated, the tumor was resected and the specimen was sent for pathology evaluation.

Histopathology was consistent with a schwannoma.
At time of discharge from the hospital to a rehabilitation facility the patient had regained some function in the lower extremities (1-2 out of 5 on neurological power exam) though he did not show any antigravity function on examination.

\section{Follow-up}

At the time of six month post-operative clinical follow-up the patient continued to have improvement in lower extremity function, presenting with antigravity strength in the lower extremities in all distributions, with ability to walk assisted with a walker with outpatient therapy. Follow up MRI did not show recurrence of tumor or intradural hematoma.

\section{Discussion}

Hemorrhagic conversion of a spinal schwannoma is rare. Several reports have described the presence of intracranial subarachnoid hemorrhage in the setting of a distal spinal schwannoma. ${ }^{4-7}$ Similarly few reports have described hemorrhagic conversion of spinal schwannomas presenting with spinal hematomas and related symptoms. ${ }^{8-16}$ These reports have described hemorrhage from spinal schwanno-

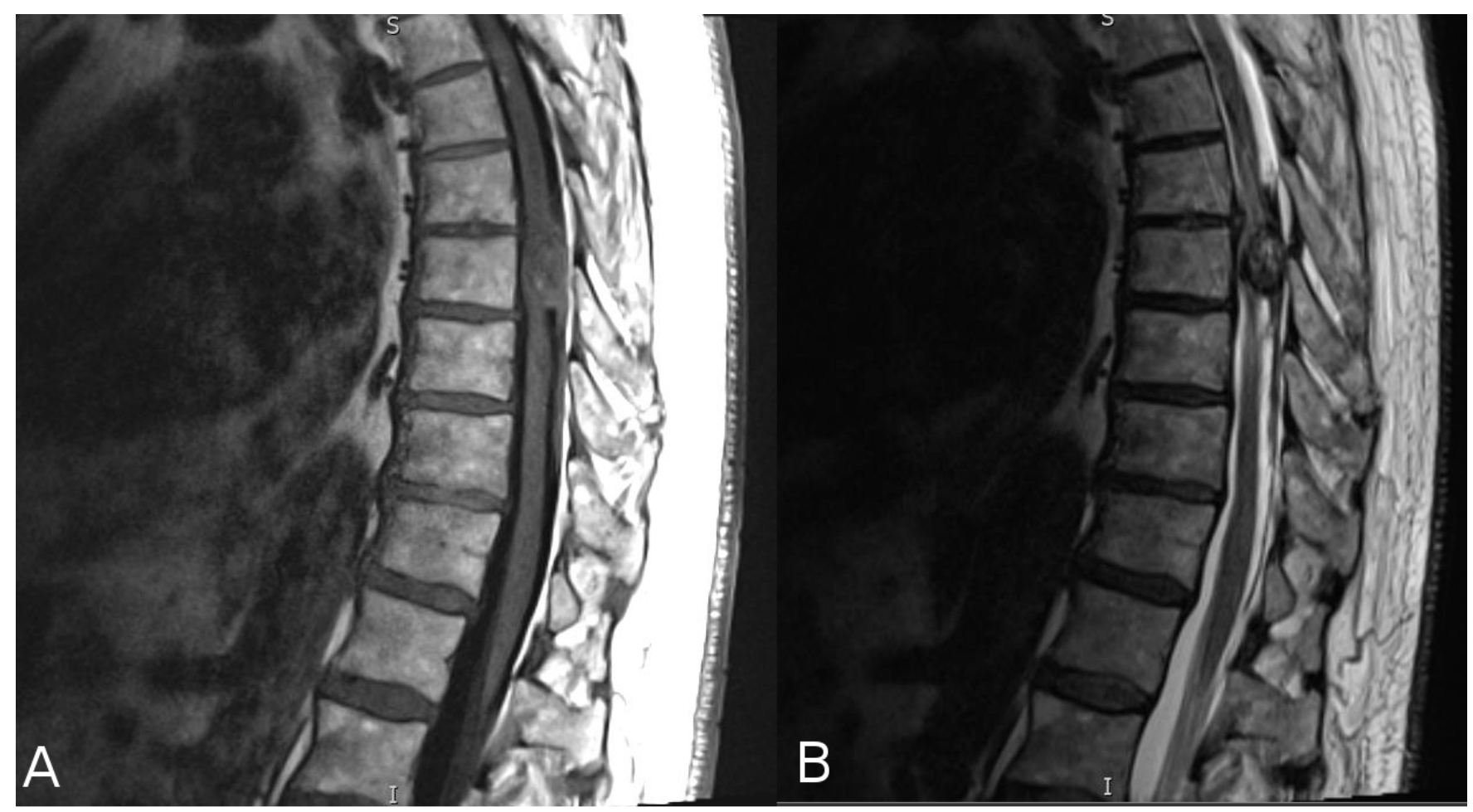

Fig. 1. Preoperative MRI of patient presenting with intradural hemorrhage. A. Sagittal T1 nonconstrat sequence. B. Sagittal T2 sequence. 
mas resulting in spinal subarachnoid, subdural and intratumoral hemorrhage and associated symptoms, with various postulated mechanisms. ${ }^{8-18}$ Table 1 and Figure 2 show a distribution in the spine of spinal schwannomas presenting with intradural subdural/ intratumoral hemorrhage, with most frequent presentation in the thoracic spine.

\begin{tabular}{|c|c|c|c|}
\hline $\begin{array}{l}\text { Case } \\
\text { number }\end{array}$ & Author (Citation) & $\begin{array}{r}\text { Location within } \\
\text { the Spine }\end{array}$ & $\begin{array}{r}\text { Type of } \\
\text { hemorrhage }\end{array}$ \\
\hline 1 & Parmer et al. (6) & $\begin{array}{r}\text { Thoracolumbar } \\
\text { (T11-L1) }\end{array}$ & $\begin{array}{r}\text { SDH } \\
\text { (Subdural) } \\
\text { SAH } \\
\text { (Subarachnoid) }\end{array}$ \\
\hline 2 & Ciapetta et al. (8) & $\begin{array}{r}\text { Craniovertebral } \\
\text { junction } \\
(\mathrm{C} 2)\end{array}$ & Intratumoral \\
\hline 3 & $\begin{array}{r}\text { Vazquez-Barquero A } \\
\text { et al. (10) }\end{array}$ & Cervical & $\mathrm{SDH}$ \\
\hline 4 & $\begin{array}{r}\text { Jenkins AL } 3^{\text {rd }} \text { et al. } \\
\text { (11) }\end{array}$ & $\begin{array}{r}\text { Lumbar } \\
\text { (L2-3) }\end{array}$ & Intratumoral \\
\hline 5 & Tanaka H et al. (12) & Thoracic & $\mathrm{SDH}$ \\
\hline 6 & Cohen ZR et al. (13) & Thoracic & $\begin{array}{r}\mathrm{SDH} \\
\text { Intratumoral }\end{array}$ \\
\hline 7 & Uemura K et al. (14) & Thoracic & Intratumoral \\
\hline 8 & Ichinose $\mathrm{T}$ et al. (16) & $\begin{array}{r}\text { Thoracolumbar } \\
(\mathrm{T} 12-\mathrm{L} 1)\end{array}$ & Intratumoral \\
\hline 9 & Ng PY (17) & Cervical & $\begin{array}{r}\mathrm{SDH} \\
\text { Intramedullary }\end{array}$ \\
\hline 10 & Smith RA (18) & Cervical & $\mathrm{SDH}$ \\
\hline 11 & Present Case & $\begin{array}{r}\text { Thoracic } \\
\text { (T8) }\end{array}$ & $\mathrm{SDH}$ \\
\hline
\end{tabular}

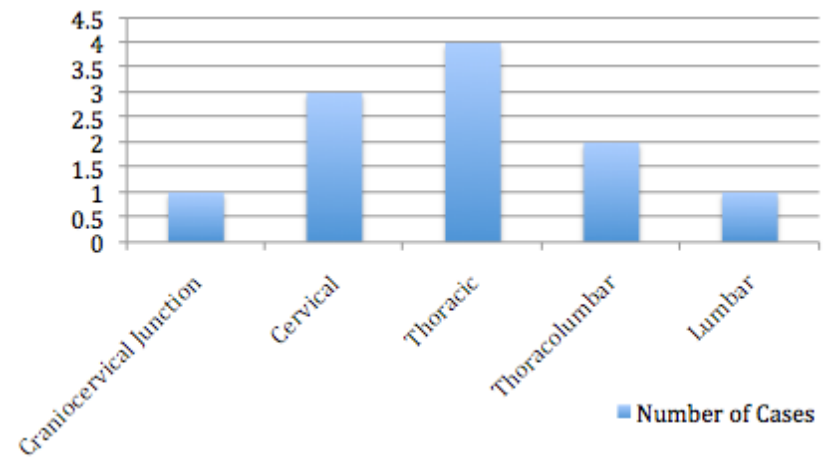

Fig. 2. Distribution within the spine of hemorrhagic spinal schwannomas (data adapted from Table 1).
Several reports have postulated changes in vascular supply as contributing factors to hemorrhage development in the setting of spinal schwannomas. Jenkins et al. describe a patient presenting with acute severe pain who was found to have a lumbar intradural extramedullary schwannoma with hemorrhage due to torsion; the authors postulate a mechanism of vascular insufficiency, likely venous, contributing to reperfusion-related hemorrhage. ${ }^{11}$ Tanaka et al. report a case of a spinal intradural hematoma from a nerve sheath tumor presenting with acute symptoms in a patient in the post-natal period two days after a normal vaginal delivery. ${ }^{12}$ The authors postulate that repetitive traction force caused by the change in posture due to change in maternal center of gravity in the immediate post-natal period may have contributed to the hemorrhage by contributing to exertion on the tumor's vascular supply from the nerve root. $^{12}$

Reports of cases of hemorrhagic schwannomas in the setting of trauma or physical exertion have been presented in the literature. Cohen et al. describes the case of a patient presenting with acute paraplegia following a minor traumatic thoracic spine injury and was found to have a hemorrhagic intradural nerve sheath tumor. ${ }^{13}$ In a case report by Uemura et al., the authors describe the case of a woman presenting with acute paraparesis following physical exertion due to hemorrhagic spinal schwannoma. ${ }^{14}$ In the present case illustration, spinal manipulation therapy may present a similar mechanical/traction mechanism of action as the physical exertion events described in previous reports, though further studies will be necessary to fully understand the mechanism.

Spinal manipulation therapy or spinal adjustment in the setting of treatments performed by various medical professionals, including practitioners of chiropractic medicine, has been associated with various described adverse effects. One systematic review of the literature since 2001 found mild to moderate adverse effects following spinal manipulation, with the most frequent serious adverse effects due to vertebral artery dissection. ${ }^{19}$ The review identified case reports in the literature reporting spinal hematomas after manipulation. ${ }^{19}$ Many reports have described epidural hematomas occurring in various parts of the spine 
following spinal manipulation therapy ${ }^{20-28}$ However, the literature lacks reports of spinal intradural hematomas following spinal manipulation therapy. We present here a unique case of a compressive thoracic intradural hematoma in the setting of a hemorrhagic conversion of a thoracic schwannoma after spinal manipulation therapy. However, we cannot exclude the possibility of a spontaneous acute hemorrhage.

Others have described hemorrhagic spinal nerve sheath tumors in the setting of anticoagulation therapy. ${ }^{15,16}$ Motomochi et al. reported a case of a patient on warfarin anticoagulation presenting with pain, numbness, lower extremity weakness, and urinary symptoms and was found to have a T10 lesion interaoperatively consistent with a nerve sheath tumor. ${ }^{15}$ Ichinose et al. also described hemorrhage within a spinal intradural schwannoma at the conus medullaris (thoraco-lumbar junction) presenting with paraparesis and urinary incontinence in a patient receiving anticoagulation, although the precise type of anticoagulant therapy is not described. ${ }^{16}$ No reports specifically describe an association with antiplatelet therapy. In our case illustration, our patient reported use of antiplatelet agents prior to presentation. Additive effects of spinal manipulation and antiplatelet therapy may have contributed to the currently described hemorrhagic presentation in the thoracic schwannoma. To our knowledge no reports to date describes a spinal intradural hematoma in the setting of both spinal manipulation therapy and antiplatelet therapy in a patient harboring a spinal schwannoma.

\section{Conclusion}

Hemorrhage from a spinal schwannoma is a rare occurrence; also rare is development of an intradural hematoma after spinal manipulation therapy. For patients harboring spinal schwannomas, tumor hemorrhage is a rare occurrence, and can be considered in the setting of additive effects from spinal manipulation therapy and antiplatelet therapy. In patients presenting with acute paraplegia from a hemorrhagic spinal schwannoma, urgent decompression of hematoma and / or tumor resection presents a therapeutic option.

\section{References}

1. Dorsi MJ, Belzberg AJ. Paraspinal nerve sheath tumors. Neurosurgery clinics of North America. 2005 April; 15(2); 217-22.

2. Jinnai T, Koyama T. Clinical characteristics of spinal nerve sheath tumors: analysis of 149 cases. Neurosurgery. 2005 March; 56(3): 510-5.

3. McCormick PC, Post KD, et al. Intradural extramedullary tumors in adults. Neurosurgery clinics of North America. 1990 July; 1(3): 591-608.

4. Kukreja S, Ambekar S, et al. Cauda equina schwannoma presenting with intratumoral hemorrhage and intracranial subarachnoid hemorrhage. Journal of Neurosurgery Spine. 2014 September; 21(3); 357-60.

5. Ji C, Ahn JG, et al. Cervical schwannoma presenting with acute intracranial subarachnoid hemorrhage. Journal of Korean Neurosurgical Society. 2010 February: 47(2); 137-9.

6. Parmar H, Pang BC, et al. Spinal schwannoma with acute subarachnoid hemorrhage: a diagnostic challenge. American Journal of Neuroradiology. 2004 May; 25(5): 846-50.

7. Corriero G, Iacopino DG, et al. Cervical neuroma presenting as a subarachnoid hemorrhage: case report. Neurosurgery. 1996 November; 39(5): 1046-9. 8. Ciappetta P, D'Urso PI, et al. Giant craniovertebral junction hemorrhagic schwannoma: case report. Neurosurgery. 2008 May; 62(5):E1166

9. Zhang HZ, Li Y, et al. Spontaneous acute hemorrhage of intraspinal canal cellular schwannoma with paraplegia: a case report. British Journal of Neurosurgery. 2014 December, 9: 1-3.

10. Vazquez-Barquero A, Pascual J, et al. Cervical schwannoma presenting as a spinal subdural haematoma. British Journal of Neurosurgery. 1994; 8(6): 739-41.

11. Jenkins AL $3^{\text {rd }}$, Ahuja A, et al. Spinal schwannoma presenting due to torsion and hemorrhage: case report and review of literature. Spine Journal. 2015 May 6; pii:S1529-9430(15)00462-3.

12. Tanaka H, Kondo E, et al. Spinal intradural hemorrhage due to a neurinoma in an early puerperal woman. Clinical Neurology and Neurosurgery. 2002 September; 104 (4): 303-5.

13. Cohen ZR, Knoller N, et al. Traumatic intratu- 
moral hemorrhage as the presenting symptom of a spinal neurinoma. Case report. Journal of Neurosurgery 2000 October; 93(2 suppl): 327-9.

14. Uemura $\mathrm{K}$, Matsumura A, et al. CT and MR presentation of acute hemorrhage in a spinal schwannoma. Surgical Neurology. 1998 September; 50(3): 219-20.

15. Motomochi M, Makita Y, et al. Spinal subarachnoid hemorrhage due to a thoracic neurinoma during anticoagulation therapy - a case report. Neurologia medico-chirurgica (Tokyo). 1981 July; 21(7): 781-4. 16. Ichinose $\mathrm{T}$, Takami $\mathrm{T}$, et al. Intratumoral hemorrhage of spinal schwannoma of the cauda equina manifesting as acute paraparesis-case report. Neurologia medico-chirurgica (Tokyo). 2009 June; 49(6): 255-7.

17. Ng PY. Schwannoma of the cervical spine presenting with acute hemorrhage. Journal of clinical neuroscience. 2001 May; 8(3): 277-8.

18. Smith RA. Spinal subdural hematoma, neurilemmoma, and actute transverse myelopathy. Surgical Neurology 1985 April; 23(4): 367-70. 19. Ernst E. Adverse effects of spinal manipulation: a systematic review. Journal of the Royal Society of Medicine. 2007 July; 100(7); 330-338.

20. Lidder S, Lang KJ, et al. Acute spinal epidural haematoma causing cord compression after chiropractic neck manipulation: an under-recognized serious hazard? Journal of the Royal Army Medical Corps. 2010 December; 156(4); 255-7.

21. Heiner JD. Cervical epidural hematoma after chiropractic spinal manipulation. American Journal of Emergency Medicine. 2009 October; 27(8); 1023. E1-2.

22. Solheim O, Jorgensen JV, et al. Lumbar epidural hematoma after chiropractic manipulation for lowerback pain: case report. Neurosurgery. 2007 July; 61(1): E170-1.

23. Domenicucci M, Ramieri A, et al. Cervicothoracic epidural hematoma after chiropractic spinal manipulation therapy. Case report and review of the literature. Journal of Neurosurgery Spine. 2007 November; 7(5); 571-4.

24. Gouveia LO, Castanho P, et al. Chiropractic manipulation: reasons for concern? Clinical Neurology and Neurosurgery. 2007 December; 109(10):
922-5.

25. Tseng SH, Chen Y, et al. Cervical epidural hematoma after spinal manipulation therapy: case report. The Journal of Trauma. 2002 March; 52(3); 585-6.

26. Ruelle A, Datti R, et al. Thoracic epidural hematoma after spinal manipulation therapy. Journal of Spinal Disorders. 1999 December; 12(6); 534-6.

27. Segal DH, Lidov MW, et al. Cervical epidural hematoma after chiropractic manipulation in a healthy young woman: case report. Neurosurgery. 1996 November; 39(5); 1043-5.

28. Whedon JM, Quebada PB, et al. Spinal epidural hematoma after spinal manipulative therapy in a patient undergoing anticoagulant therapy: a case report. Journal of Manipulative and Physiological Therapeutics. 2006 September; 29(7): 582-5.

\section{Disclosures \& COI}

$\mathrm{AH}$ and JPW have no disclosures. CRG is a UNCF Merck Postdoctoral Fellow and has received an award from the Burroughs Wellcome Fund. AB is the recipient of a research grant from DePuy Spine and serves on the clinical advisory board of MedImmune, LLC. DS is a consultant for DePuy, Medtronic, Orthofix, and Globus. TW is a recipient of a research grant from Eli Lilly and Company and The Gordon and Marilyn Macklin Foundation. ZLG has disclosures of stock ownership in US Spine and Spinal Kinetics, consulting, speaking and teaching for the AO Foundation and Research support from Depuy, NREF, AOSpine and AO North America. The authors report no external source of funding for this manuscript.

\section{Corresponding Author}

Alia Hdeib, MD, 11100 Euclid Avenue, HAN 5042,
Cleveland, OH 44106

Published 20 December 2016.

This manuscript is generously published free of charge by ISASS, the International Society for the Advancement of Spine Surgery. Copyright @ 2016 ISASS. To see more or order reprints or permissions, see http://ijssurgery.com. 